\title{
Overweight and Obesity among Adolescents in Kano, Nigeria
}

\section{Shehu M Yusuf, Muhammad S Mijinyawa, Baba M Musa, Ibrahim D Gezawa and Andrew E Uloko*}

Departments of Medicine, Aminu Kano Teaching Hospital and Bayero University Kano, Nigeria

\begin{abstract}
Background: Childhood and adolescent obesity is a global public health concern because of associated increased risk of cardiovascular diseases later in life. Although there are several studies on childhood obesity in Nigeria, few have assessed it in adolescents.
\end{abstract}

Objectives: This study intends to assess the prevalence of overweight and obesity in adolescents in urban northern Nigeria.

Method: A cross sectional school based survey was conducted to determine the prevalence of overweight and obesity. Stratified sampling was used to select 718 students. Their weight and height were measured and used to compute the Body Mass Index (BMI). Overweight and obesity were defined using the International Obesity Task Force (IOTF).

Results: The prevalence of obesity and overweight were $0.84 \%$ and $1.98 \%$ respectively; with advancing age as a risk factor for both overweight and obesity. Multivariate logistic regression showed that the risk of overweight was almost two times higher with advancing age adjusted odds ratio of $\{1.79\}$ with a p-value of $\{0.03\}$ and C.I. $\{1.05-3.09\}$, adjusted for gender and school type.

Conclusion: The data suggest the prevalence of overweight and obesity are low, and that advancing age is a risk factor for obesity.

Keywords: Prevalence; Overweight; Obesity; Adolescents; Nigeria

\section{Introduction}

Adolescent malnutrition (underweight or overweight) not only impacts future adult physique and sense of self-esteem, it also affects future metabolic and cardiovascular outcomes [1]. Overweight and obesity are associated with risk of developing diabetes mellitus and cardiovascular diseases [1].

The prevalence of childhood and adolescent obesity has increased in the developed world. The same trend has been observed in developing countries in recent years. It has thus become necessary to track these changes in order to reverse the negative impact they portend on public health [2].

While there are several studies that have addressed childhood obesity in Nigeria, few have evaluated its occurrence in adolescents. Even among these studies are disparities, such as a 2007 study in Shagamu (south western Nigeria) showing a prevalence of overweight of $8.1 \%$ in males and $8.1 \%$ in females. It further showed a low prevalence of obesity of $2.7 \%$ in males and $1.9 \%$ in females. In contrast Another study in Ajoakuta (southwestern Nigeria) reported a higher figure of overweight/obesity as $17.3 \%[3,4]$. This could be due to socioeconomic differences in sub populations studied. A study in Jos, Northern Nigeria found among males $17.2 \%$ was overweight, with $4.2 \%$ obese. Among women $23.5 \%$ were overweight and $4.5 \%$ were obese [5]. A study in the Niger delta southern Nigeria found $22.04 \%$ overweight and 49.34 $\%$ were obese [6]. In Abia southeastern Nigeria The prevalence of overweight/obesity in the population was $28.4 \%$, contrast to another the report form in Imo south eastern Nigeria were prevalence of obesity was $6.0 \%$,while in a community based study in Benue the prevalence of overweight was $9.7 \%$ and obesity $1.8 \%$ [7-9].

Attempts were made in developing a "gold standard" reference population for determining thinness, overweight and obesity. In 2007, the World Health Organization developed a reference population for classifying overweight and obesity based on the anthropometric measures of children and adolescents from some countries with average socioeconomic status. However these references are limited in their applicability because differences in growth pattern are seen across economic divides $[10,11]$. Thus while such a reference could be used in developing countries; a different standard would have to be used in developing countries.

This study aimed to determine the prevalence of overweight and obesity among secondary school adolescents in Kano, Nigeria, in accordance with World Health Organization standard reference.

\section{Study area}

The study was carried out in Kano, the Capital city of Kano State in Northwest Nigeria, located between latitude $12^{\circ} 00^{\prime}$ North and longitude $8^{\circ} 13^{\prime}$ East. It occupies a total area of 499 square kilometers with an estimated population of $2,828,861$ (2006 census) [12]. The principal inhabitants of the city are the Hausa-Fulanis, although a good number of other ethnic groups, such as the Igbos and Yorubas also inhabit some part of the city. The major language spoken is Hausa, although English is also widely spoken in schools, offices and markets. Kano is acclaimed Nigeria's center of commerce with its economic significance dating back to the precolonial era when it served as the southernmost point of the famous trans-Sahara trade routes. A sizeable number of its inhabitants are also engaged in farming, while the remainder is in the civil service.

\section{Study design and population}

A cross-sectional survey was carried out to determine the prevalence of overweight and obesity and obesity among adolescent (boys and girls) aged 13-18 years attending secondary schools in Kano metropolis. Both private and government owned schools were selected in order to have a fair representation from the different social strata of the society.

*Corresponding author: Dr. Andrew E Uloko, Department of Medicine, Aminu Kano Teaching Hospital, P.M.B. 3452 Kano, Nigeria, E-mail: andyuloko@yahoo.com

Received July 29, 2013; Accepted August 27, 2013; Published August 30, 2013

Citation: Yusuf SM, Mijinyawa MS, Musa BM, Gezawa ID, Uloko AE (2013) Overweight and Obesity among Adolescents in Kano, Nigeria. J Metabolic Synd 2: 126. doi:10.4172/2167-0943.1000126

Copyright: @ 2013 Yusuf SM, et al. This is an open-access article distributed under the terms of the Creative Commons Attribution License, which permits unrestricted use, distribution, and reproduction in any medium, provided the original author and source are credited. 


\section{Sampling technique}

A comprehensive list of all the schools in Kano was collected from the State Ministry of Education. The schools for the study were then selected with the use of the simple random technique applied through the table of random numbers. With the use of the stratified sampling technique, proportionate allocation was given to each school to make up the required sample size depending on the population of the students in the school.

All students of the chosen schools within the study age group were considered. However, in each school, systematic sampling method was employed in which the students were given numbers serially according to their classroom register from class 1 to class 6 , thereby giving each student an equal chance. The random number table was used to select the first number and thereafter students were picked at regular interval (sample interval) so as to meet the sample size requirement in the school. This sample interval (SI) was determined by dividing the total number of students in the selected schools by the sample size: $9,758 / 1000=9.758=10$.

A total of 1,000 students were selected for the study, out of which 718 consisting of 309 males and 409 females had complete data. Only those with complete data taken were included in the study analysis. They were apparently healthy students aged between 13 to 18 years mainly composed of the indigenous Hausa ethnic group, Hausa. Excluded from the study were non-Nigerians and students that were ill.

Ethical approval for this study was obtained from the ethics committee of the Aminu Kano Teaching Hospital, Kano. Informed consent was gotten from the schools administration and parents. Permission was also obtained from the local education authority and the principals of the selected schools. The purpose, process and intent of the study were explained to the participants. Bio-demographic information was obtained from each of the participants, including bio-data on age (as at last birthday) and sex. Students attending government schools were considered to be largely from low socioeconomic backgrounds; while those attending private schools were considered to be from high socio economic background.

\section{Anthropometric measurements}

All measurements were made by persons trained on the proper techniques of measuring height and weight. Weighting scale was standardized by the technicians, and weight was taken based on internationally accepted standards for weight measurements. The weighing scales we reassessed for proper calibration each morning before weighing were done. The weight of each student was measured, with the student bare footed and with light clothing, using WEYLUX weighing scale, Model 424J; Sliding Beam Column Scale, (Short Pillar with height of $560 \mathrm{~mm}$ ). The measurements were recorded to the nearest one (1) kilogram $(\mathrm{Kg})$. Their height was measured using ACCUSTAT Ross Stadiometer, 44817, manufactured by Genentech Incorporated. The students were asked to stand erect with the heels, buttocks, upper back and occiput against the stadiometer. The measurements were recorded to the nearest $1 \mathrm{~cm}$. The BMI was then computed using the standard formula $\left[\mathrm{BMI}=\right.$ weight $(\mathrm{kg}) /$ height $\left.\left(\mathrm{m}^{2}\right)\right]$.

Overweight and obesity were determined using the International Obesity Task Force (IOTF) BMI cutoff points for children and adolescents. These age-and gender-specific cutoff points were derived from a large international sample with regression techniques, by passing a line through the adult cutoff points at 18years. Participants with BMI values corresponding to BMI of $18.5-24.9 \mathrm{~kg} / \mathrm{m}^{2}$ were classified as normal, participants with BMI values corresponding to BMI of 25 to $29.9 \mathrm{~kg} / \mathrm{m}^{2}$ were classified as overweight, and participants with BMI values corresponding to BMI of $30 \mathrm{~kg} / \mathrm{m}^{2}$ were classified as obese.

\section{Data analysis}

Statistical analysis was carried out using statistical STATA version 11.0. Quantitative variables were assessed using $t$ test while qualitative ones were assessed using chi square. Descriptive statistics of mean and standard deviation were used to examine the age- and gender-specific anthropometric indices. The estimator for this study is the prevalence of overweight and obesity measures based on the IOTF, and NHANES III cutoff point. Differences between parameters compared were considered to be statistically significant within $95 \%$ confidence interval, a P-value $<0.05$.

\section{Result}

A total of 718 students participated in the study, out of which $57 \%$ were females and $43 \%$ were males. The median age was 16 years with a range of 13-19 years. The median height was 1.57 meters, with a range of $1.20-1.88$ meters while the median weight was 45 kilogram $[\mathrm{kg}]$ with a range of $24-120 \mathrm{~kg}$. The median BMI was $17.86 \mathrm{~kg} / \mathrm{m}^{2}$ with a range of $11.31-42.97 \mathrm{~kg} / \mathrm{m}^{2}$.

The correlation of age against height, weight and BMI for students studied showed a linear trend; with a Pearson correlation coefficient $[\mathrm{r}]$ being [0.52], [0.49], [0.29] for height weight and BMI respectively as seen in Figures $1 \mathrm{a}, 1 \mathrm{~b}$ and $1 \mathrm{c}$ respectively.
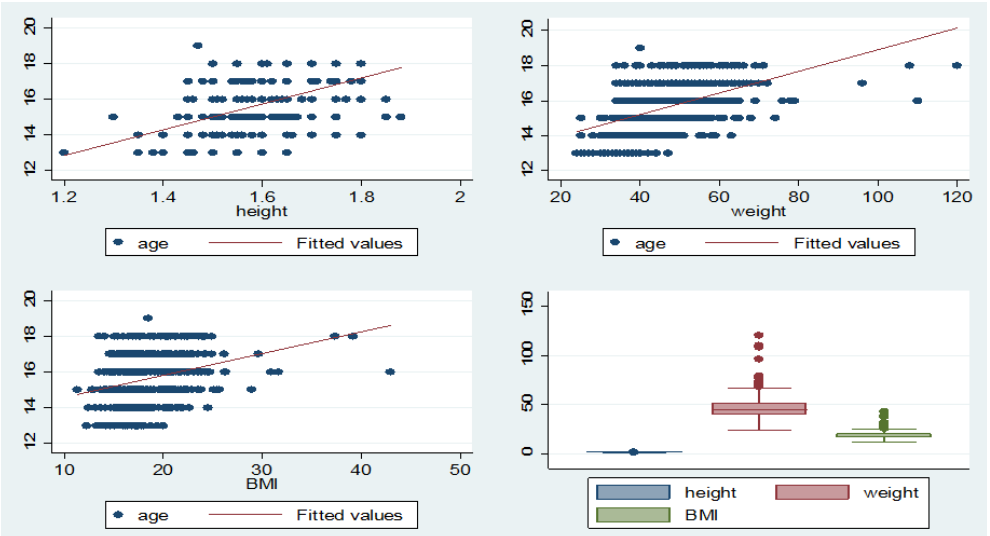

Figure 1: Correlation between age and anthropometric measurements and Box plot of anthropometric measurements. 


\begin{tabular}{|c|c|c|c|c|c|c|c|c|c|}
\hline \multirow{2}{*}{ AGE (years) } & \multicolumn{3}{|c|}{ Weight \pm SD } & \multicolumn{3}{|c|}{ Height \pm SD } & \multicolumn{3}{|c|}{$\mathrm{BMI} \pm \mathrm{SD}$} \\
\hline & $\mathrm{F}$ & $M$ & P-value & $\mathrm{F}$ & $M$ & $P$ value & $\mathrm{F}$ & $M$ & $P$ value \\
\hline 13 & $35.1+4.93$ & $31.4+4.93$ & 0.02 & $1.46+.05$ & $1.40+0.08$ & 0.01 & $16.27+1.65$ & $15.78+1.59$ & 0.32 \\
\hline 14 & $41.31+6.39$ & $39.54+8.77$ & 0.27 & $1.53 \pm 0.05$ & $1.51 \pm 0.10$ & 0.33 & $17.48 \pm 2.31$ & $16.91 \pm 1.89$ & 0.23 \\
\hline 15 & $44.65 \pm 7.27$ & $44.60 \pm 7.88$ & 0.97 & $1.56 \pm 0.07$ & $1.58 \pm 0.85$ & 0.080 & $18.35 \pm 2.87$ & $17.78 \pm 2.27$ & 0.17 \\
\hline 16 & $46.58 \pm 10.14$ & $50.17 \pm 8.00$ & 0.011 & $1.57 \pm 0.070$ & $1.64 \pm 0.07$ & 0.000 & $18.83 \pm 3.85$ & $18.52 \pm 2.28$ & 0.54 \\
\hline 17 & $47.5 \pm 8.16$ & $52.45 \pm 9.09$ & 0.001 & $1.57 \pm 0.64$ & $1.67 \pm 0.72$ & 0.000 & $19.09 \pm 2.82$ & $18.67 \pm 2.50$ & 0.35 \\
\hline 18 & $51.7 \pm 15.25$ & $59.46 \pm 15.30$ & 0.09 & $1.58 \pm 0.079$ & $1.70 \pm 0.06$ & 0.000 & $20.47 \pm 5.04$ & $20.48 \pm 4.69$ & 0.99 \\
\hline
\end{tabular}

Table 1: Gender related anthropometric pattern.

\begin{tabular}{|c|c|c|c|c|}
\hline Gender & Normal weight[97.2\%] & Overweight[1.98\%] & Obese[0.84\%] & Total \\
\hline Females & 395 & 10 & 4 & 409 \\
\hline Males & 303 & 4 & 2 & 309 \\
\hline Total & 698 & 14 & 6 & 718 \\
\hline \multicolumn{5}{|c|}{ Ages (years) } \\
\hline 13 & 46 & 0 & 0 & 46 \\
\hline 14 & 94 & 1 & 0 & 95 \\
\hline 15 & 193 & 5 & 0 & 198 \\
\hline 16 & 180 & 5 & 3 & 188 \\
\hline 17 & 141 & 3 & 1 & 145 \\
\hline 18 & 44 & 0 & 2 & 46 \\
\hline Total & 698 & 14 & 6 & 718 \\
\hline
\end{tabular}

Table 2: Sex and age specific prevalence of overweight and obesity.

The mean height, weight and BMI for all ages were $1.58+/-\mathrm{SD}$ meters, $46.16 \mathrm{~kg}$, and $18.34 \mathrm{~kg} / \mathrm{m}^{2}$ respectively. The box plot of weight and BMI show a skewed distribution with higher value outliers (Figure 1d).

Table 1 represents the mean and standard deviation of height, weight and BMI for each age band disaggregated by gender. All anthropometric indices measures showed a sustained increase with age for all genders. Females tend to have statistically significantly more height and weight for age band 13; while males have more height and weight for age band 16 and 17, and only statistically significant higher height than females for age 18 year. Similar gender related differences were not observed for BMI.

The prevalence of obesity and overweight were $0.84 \%$ and $1.98 \%$ respectively. There was no statistically significant association between obesity with gender and age; with a level of significance at $\mathrm{p}=0.439$ and $\mathrm{p}=0.227$ respectively, as depicted in Table 2 .

However, in a multivariate logistic regression analysis adjusted simultaneously for socio demographic factors (age, sex and social status), shows that the risk of overweight there was an almost twofold increase in the risk of being overweight, which is higher with advancing age, an odds ratio of $\{1.79921\}$ with a p-value of $\{0.033\}$ and C.I. $\{1.048$ - 3.088\}. While the risk of being overweight was found to increase by one and a half fold times more with increasing weight; odds ratio $\{1.5\}$ P- value $\{0.001\}$ with C.I. $\{1.21-1.97\}$; even after adjusting for age.

\section{Discussion}

The adolescents in this study were in urban northern Nigeria, and appear to have the similar pattern of growth compared to those in earlier studies in Nigeria. The height, weight and BMI of this study subjects are similar to what was reported from south west Nigeria [13].

The range of anthropometric measures of studied students was lower than the WHO standard even when disaggregated by gender. This finding also shows that their anthropometric measures are lower than the global reference population. This has been ascribed to delayed growth seen in Africans during early adolescence. The low height for age will suggest some degree of stunting. The trend of relative low anthropometric measures noted compared to global standard is similar to what is reported in other parts of Africa [13-15]. This apparent difference has been attributed to malnutrition and recurrent parasitic infection seen in African children [16,17].

Overall adolescent in northern Nigeria tend to be lower than the WHO reference population up till the ages of 17-18 years when "catch up growth" occurs. Our study found a strong linear trend of age for height, weight and BMI. This suggests an evenly sustained growth across all ages. Being in an urban area availability of food is fairly maintained. Most of the studied subjects are wards of a civil servant or traders, as such are raised by families with fairly sustained income their growth has equally been fairly sustained.

Although we found apparent numeric gender related BMI differences, it was not statistically significant. This is in contrast to another adolescent study in Ajoakuta, Nigeria which found boys to be slightly more obese than girls; the observation in our study may be due to the higher sample size we adopted compared to the stated study [18]. It could also possibly be due to genetics, environmental and behavioral habits like differences in eating pattern between the tribes in Ajoakuta and the predominantly Hausa-Fulani stock in Kano.

The prevalence of obesity and overweight were $0.84 \%$ and $1.98 \%$ respectively. There was no statistically significant association between obesity with gender and age. This finding is similar to an earlier study from Shagamu, Nigeria [19]. It is however in contrast to other studies from southern Nigeria where Ajibode reported prevalence of obesity at $3.2 \%$ and $5.1 \%$ in males and females respectively; and that of Owa et al. reported that a cumulative $18 \%$ prevalence of obesity $[19,20]$. This may be due to different rates of epidemiological transition between the far northern Nigeria and the rest of the countries. In the far north families still tend to adhere to traditional meals and the children are engaged in a lot of outdoor activities [3]. It may also be explained by innate genetic differences. However A cross-sectional study of 1,599 children and adolescents 5 to 18years of age was conducted in four urban 
towns (Lagos, Port Harcourt, Nsukka, and Aba) in southern Nigeria. It showed a prevalence rates of $11.4 \%$ and $2.8 \%$ for overweight, obesity respectively [21]. There finding of low obesity is similar to finding from our study. Another study in Tarka northern Nigeria showed a similarly low prevalence to our study with a value of $7.5 \%$ [22]. Likewise, a study in Abeokuta reported 5\% obesity in adolescent [23]. This suggests that even among areas sharing similar socio-cultural characteristics, there could be heterogeneity in pattern of obesity due to peculiar local circumstances.

The finding that females in this study tends to have more height and weight for age band 13; while males have more height and weight for age band 16 and 17, and statistically significant higher height than females for age band 18 years, may be explained by the fact that puberty tends to occur earlier in females, with the males catching up later in life.

While the risk of being overweight was found to increase by one and a half fold times more with increasing weight; even after adjusting for age. This may be explained by the fact that in Africans, there is no commensurate increase in height compared to weight with advancing age.

While it is known that obesity can appear at any age, the risk of obesity increases with advancing age, due to hormonal alterations and a sustained reduction in active lifestyles. Whereas obesity in adolescent may be related to increased exposure and usage of energy dense and fatty meals; in the elderly it is due to a reduction in muscle mass with age and attendant reduction in metabolism. These changes lead to reduction in calorie burning by the body, with a good proportion of what is eaten stored by the body and consequently leading to obesity.

In contrast, while the risk of overweight was found to be one and a half times more with increasing weight; even after adjusting for age. This may be explained by the fact that in Africans, there is no commensurate increase in height compared to weight with advancing age.

Having identified the burden of overweight and obesity in adolescent there is the need to put in place clear cost effective evidence based policy policies, such as reduction in high calorie diet marketing to adolescents, which will retard or perhaps reverse the trend of a rising obesity in Nigeria. There is also the need to have an assessment of the secular trend of malnutrition to be able to properly plan for such interventions.

The main strength of our study is that we established the prevalence of overweight and obesity in a representative sample of adolescents in our setting, using well trained assistants who undertook all anthropometric measurements under close supervision. In addition, this is the first study on anthropometric indices among adolescents and young adults in Kano, Nigeria. We also appreciate the fact that our study has limitations. The cross-sectional nature of the study makes generalization of our findings to the entire population difficult. Classification of social status in our study was not based on any of the available standard questionnaires. This may have affected our related to social status. Notwithstanding, the result of this study can be extrapolated to populations with similar socioeconomic attributes. Thus the finding low (incomplete sentence) though our findings are by no means novel, they confirm previous reports of low prevalence of overweight and obesity among adolescents in Nigeria. Our study also provides baseline data for similar studies in the future especially in Northern Nigeria where such data are lacking.

\section{Conclusion}

There is a low prevalence of adolescent overweight and obesity in
Northern Nigeria. However there is a need to put in place evidence based policies that will prevent their emergence which in turn will lead to a public health challenge.

\section{References}

1. Lazzeri G, Rossi S, Pammolli A, Pilato V, Pozzi T, et al. (2008) Underweight and overweight among children and adolescents in Tuscany (Italy). Prevalence and short-term trends. J Prev Med Hyg 49: 13-21.

2. Wang $Y$, Lobstein $T$ (2006) Worldwide trends in childhood overweight and obesity. Int J Pediatr Obes 1: 11-25.

3. Akinpelu1 AO, Oyewole OO, Oritogun KS (2008) Overweight and Obesity: Does It Occur In Nigerian Adolescents in an Urban Community? International Journal of Biomedical and Health Sciences 4:11-17.

4. Ejike CECC, Ugwu CE, Ezeanyika LUS (2010) Physical growth and nutritional status of a cohort of semi-urban Nigeria adolescents. Pak J Nutr 9: 392-397.

5. Puepet FH, Zoakah Al, Chuhwak EK (2002) Prevalence Of Overweight And Obesity Among Urban Nigeria Adults In Jos. Highland Medical Research Journal 1: 13-16.

6. Adienbo OM, Hart VO, Oyeyemi WA (2012) High Prevalence of Obesity among Indigenous Residents of a Nigerian Ethnic Group: The Kalabarisin the Niger Delta Region of South-South Nigeria. Greener Journal of Medical Sciences 2: 152-156.

7. Ejike CE, ljeh II (2012) Obesity in young-adult Nigerians: variations in prevalence determined by anthropometry and bioelectrical impedance analysis, and the development of \% body fat prediction equations. Int Arch Med 5: 22.

8. Iloh G, Amadi AN, Nwankwo BO, Ugwu VC (2011) Obesity in adult Nigerians: a study of its pattern and common primary co-morbidities in a rural Mission General Hospital in Imo state, South-Eastern Nigeria. Niger J Clin Pract 14 212-218.

9. Musa DI, Toriola AL, Monyeki MA, Lawal B (2012) Prevalence of childhood and adolescent overweight and obesity in Benue State, Nigeria. Trop Med Int Health.

10. Cole TJ, Bellizzi MC, Flegal KM, Dietz WH (2000) Establishing a standard definition for child overweight and obesity worldwide: international survey. BMJ 320: $1240-1243$.

11. de Onis M, Onyango AW, Borghi E, Siyam A, Nishida C, et al. (2007) Development of a WHO growth reference for school-aged children and adolescents. Bull World Health Organ 85: 660-667.

12. National Population Commission. Kano State National Population Commission Office, Makurdi, Nigeria.

13. Cameron N (1991) Human growth, nutrition, and health status in Sub-Saharan Africa. Yearb Phys Anthropol 34: 211-250.

14. Cameron N, Gordon-Larsen P, Wrchota EM (1994) Longitudinal analysis of adolescent growth in height, fatness, and fat patterning in rural South African black children. Am J Phys Anthropol 93: 307-321.

15. Cameron N, Kgamphe JS, Leschner KF, Farrant PJ (1992) Urban-rura differences in the growth of South African black children. Ann Hum Biol 19 23-33.

16. Abioye-Kuteyi EA, Ojofeitimi EO, Aina OI, Kio F, Aluko Y, et al. (1997) The influence of socioeconomic and nutritional status on menarche in Nigerian school girls. Nutr Health 11: 185-195.

17. Akande B (1989) Some socio-cultural factors influencing fertility behaviour: a case study of Yoruba women. Biol Soc 6: 165-170.

18. Chukwunonso ECC, Chidi UE, Lawrence EUS (2010) Physical Growth and Nutritional Status of a cohort of Semi-Urban Nigerian Adolescents. J Nutr 9 : 392-397.

19. Akesode FA, Ajibode HA (1983) Prevalence of obesity among Nigerian schoo children. Soc Sci Med 17: 107-111.

20. Owa JA, Adejuyigbe O (1997) Fat mass, fat mass percentage, body mass index, and mid-upper arm circumference in a healthy population of Nigerian children. J Trop Pediatr 43: 13-19.

21. Ene-Obong H, Ibeanu V, Onuoha N, Ejekwu A (2012) Prevalence of overweight obesity, and thinness among urban school-aged children and adolescents in southern Nigeria. Food Nutr Bull 33: 242-250. 
Citation: Yusuf SM, Mijinyawa MS, Musa BM, Gezawa ID, Uloko AE (2013) Overweight and Obesity among Adolescents in Kano, Nigeria. J Metabolic Synd 2: 126. doi:10.4172/2167-0943.1000126

Page 5 of 5

22. Goon DT, Toriola AL, Uever JN, Wuam S, Toriola OM (2011) Prevalence of body weight disorders among adolescent school girls in Tarka, Nigeria. Minerva Pediatr 63: 467-471.
23. Senbanjo IO, Oshikoya KA (2012) Obesity and blood pressure levels of adolescents in Abeokuta, Nigeria. Cardiovasc J Afr 23: 260-264. 